Dorota Klimecka-Tatar ${ }^{1}$, Piotr Sygut ${ }^{2}$, Pawet Szklarzyk ${ }^{3}$

\title{
THE WORK EFFICIENCY EVALUATION OF THE INDUCTION FURNACE IN DENTAL LABORATORIES
}

\begin{abstract}
This paper presents the results of Overall Equipment Effectiveness (OEE) indicator measurements of the induction furnace used in the dental laboratory. Analysis of factors OEE allowed identifying the most important reasons, which reduce the performance time of the machine. Based on the measurements, it was found that the best way to improve the performance of the machine is to increase the skills of workers operating the furnace, and the implementation of SMED techniques in machine retooling.
\end{abstract}

Key words: Overall Equipment Effectiveness, OEE, induction furnace, casting method

\section{Casting technique in dental prosthetics}

In dental prosthetics casting techniques are very important. Casting in this field of science is the most important technique of metal of prostheses or crown parts preparation. Casting method gives the ability to create complicated, desired shape and size by filling by liquid alloy of suitably prepared molds.

Many elements currently manufactured by casting can be performed by other techniques such as forging, pressing, welding and mechanical processing. However, the molding, which in relation to these techniques of production technique is undoubtedly the most complicated and difficult, successfully competing with them, being often an indispensable technology both from the point of technical and economic view. The dental technology is simply irreplaceable, especially considering the fact

1 dr inż., Czestochowa University of Technology, Faculty of Management, Institute of Production Engineering, e-mail: klimt@ wip.pcz.pl

2 dr inż., Czestochowa University of Technology, Faculty of Management, Institute of Production Engineering, e-mail: piotr.sygut.wz@gmail.com

3 mgr inż., Czestochowa University of Technology, Faculty of Management, Institute of Production Engineering, e-mail: szklarzyk.pawel@o2.pl 
that the crown embossed been almost completely withdrawn from the market. One technique for producing a threat is a full-ceramic restorations based on zirconium oxide synthesized (KORDASZ P., WOLANEK Z. 1983, MAJEWSKI S. 2000).

The possibility of casting preparing with thin and good quality, complicated structure and different sizes, without shrinkage cavities, cracks, and other defects rarefaction casting, is closely associated with the casting characteristics of the alloys used in dentistry (POLAK A. 2005). Among the technological properties of metals and alloys, which directly and indirectly affect on the casting, especially to obtain a specific design, with the required operating parameters, the relevant surface cleanliness and dimensional accuracy, are chemical composition, structural features, the phase composition, the thermal characteristics (melting and solidification), fluidity, etc. All properties have an effect during the casting to mold and during the crystallization process. In addition, it is important to follow accordingly to the instructions of manufacturers, including the use of appropriate techniques to the respective alloys (induction melting technique or gas). However, the melting or casting method are largely determined by technical laboratory equipment.

For casting of dental alloys there are used several types of casting techniques, which use the centrifugal force. The most important techniques for casting /melting in dental technology include those using Volta's arc, flame of oxy-acetylene torch as a heat source in a melting process, induction furnace and the Autocast method (RADOMSKA K., KLIMECKA-TATAR D. 2013). It should be underline, that any technique of casting/melting can lead to defects, deficiencies, inappropriateness of dental alloy. The quality of this cast is closely connected with the experience of a dental technician, during the casting /melting of metallic structures. In the more specialized devices (e.g. induction furnace) can be used the protective atmosphere, preventing contamination of alloy with other elements (ORLICKI R., KŁAPTOCZ B. 2003). Processes with vacuum reduces the amount of oxide inclusions in the melt, and these contribute to reduced carbon monoxide partial pressure of the metal, which reduces to 
a minimum the loss of chromium during the refining (the oxidation of oxygen in the metal bath) (ŚPIEWAK R., PIĘTOWSKA J. 2006).

It is important, however, the same operational efficiency of such a furnace. For failure to ensure an adequate level of technical equipment may also result in the formation of many of the wrong products. Due to the fact that the cost of dental prostheses are quite high, particular attention is given to ensure the proper use and maintenance of machinery.

This paper presents the results of the analysis of the efficiency of the machine, which is the induction furnace used in dental laboratory.

\section{OEE (Overall Equipment Effectiveness) indicator}

The OEE indicator (Overall Equipment Effectiveness), equipment utilization indicator, is an international standard for measuring the efficiency of machines.

The OEE analysis starts with the determination of the total production time in which manufacturer is able to produce. The total production time is subtracted with planned downtime, which include all events that should be excluded from the analysis of efficiency, because at that time there was no intention to production carry out (eg. breaks, interruption, training, planned maintenance, lack of orders from customers). The remaining time is called the scheduled time of production. OEE analysis starts from scheduled time production time and analyze the efficiency losses that occur with task constraints and eliminate these losses. There are three general categories of losses for consideration: downtime, loss of performance and quality.

OEE is the result of the other three measurable sub-indicators: Availability, Performance, and Quality. The OEE indicator is calculated according to the formula:

$$
O E E=A \cdot P \cdot Q
$$

Availability (A) indicator takes into account all outages, which include all events that will stop the production for a certain period of time (usually a few minutes), examples are: failure, lack of materials, retool- 
ing, maintenance of machinery, etc. The retooling time is taken for the analysis of OEE as in some sense downtime. The retooling time cannot be fully eliminated, but it can in most cases be reduced. Remaining available time is sometimes called operating time.

Performance $(\mathrm{P})$ indicator takes into account the loss of production speed, all the factors that cause that the production goes with less than the maximum speed (e.g. micro-downtime, work at a reduced speed). The remaining time is sometimes called net operating time.

Quality (Q) indicator as a part of OEE indicator represents the amount of good units produced as a percentage of the total amount of units. The Quality indicator is a pure measurement of Process Yield that is designed to exclude the effects of Availability and Performance. The losses due to defects and rework are called quality losses.

\subsection{Characteristic of dental laboratory work}

In this study the OEE indicator for efficiency use of induction furnace in dental laboratory was assessed. The ratio was calculated based on 20 days in 8-hour system of work. It should be noted that the castings executed in the dental laboratory are not mass production, each cast requires an individual model and mold. The use of the furnace involves a cyclic change of forms and casting metal (a type of mold and the material is largely determined by individual order). For example, casts for crowns and bridges require far less material and less complicated form, and therefore the remelt and casting process itself is much shorter than is the case with skeletal, complete dentures and. Runtime of a single cast execution was taken as 60 minutes, which is the average value.

\subsection{The results - OEE indicator for induction furnace in a dental laboratory}

The analysis of the machine efficiency (OEE) was determined based on the data collected during the 20 days of work in 8 -hour system. On the 
basis of the data set the structure of loss in the availability of the machine is conducted on Fig. 1.

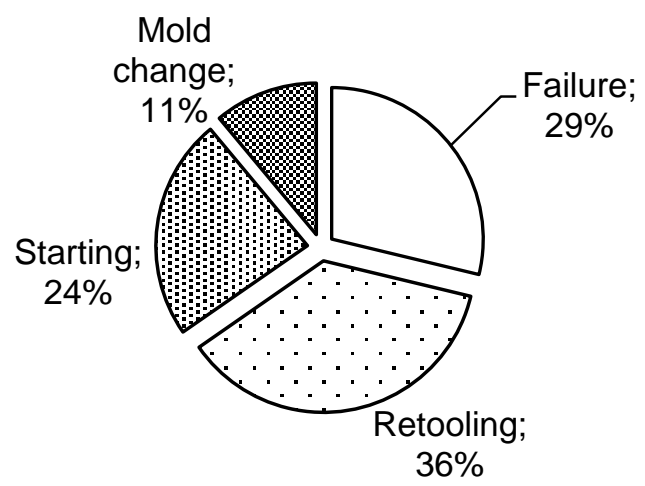

Source: own study

Fig. 1. Structure of machine's availability losses

As is clear from the data presented in the Fig. 1. the greatest losses in the machines availability generate retooling of the machine, about $36 \%$ of the time (availability loss time). Subsequently, large losses of the availability are caused by failure of the furnace and the furnace starting, these values do not exceed $30 \%$ of the availability loss. However, the smallest loss of time's availability, are generated by the mold change.

In Fig.2-4 presented charts depicting percentage of variable availability of machines, machine performance and quality of production in the 20-day study period. The graph also noted the trend line, each of these factors. As follows from the presented figure in the case of Availability indicator, the largest share of which was recorded (during the study ranged) around 90\% percent, which is consistent with world standards. However, disadvantage is, that for several days the machine was a significant decrease in machine's availability, up to $30 \%$. A review of the data used to the study indicate that the large decline during the machine's availability is due to a number of equipment failures. The trend line indicates that the availability of the furnace decreased with study time. A similar dependence for Quality and Performa indicator was reported. The 
trend line clearly indicated a decrease in utilization and reduce of the quality factor, despite the fact that within a few days there has been $100 \%$ quality, but the quantity produced pieces was not close to normal production.

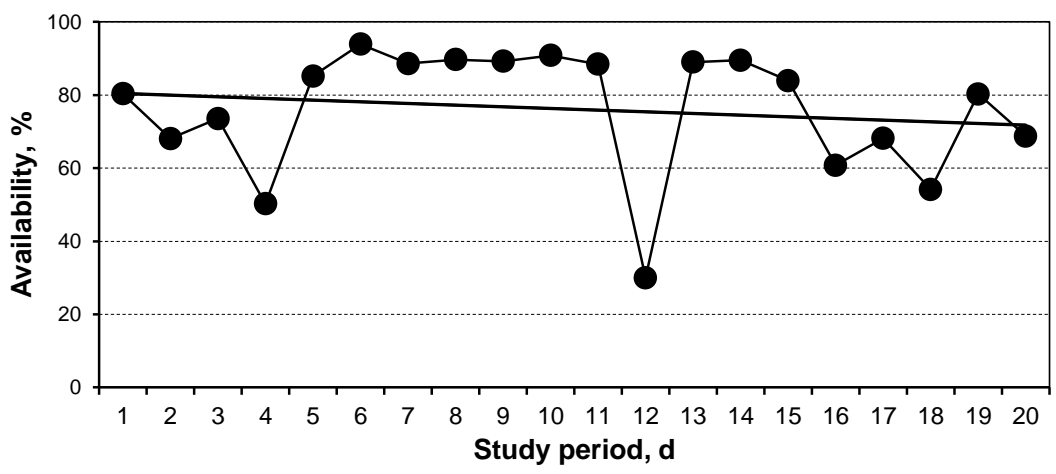

Fig.2. The distribution of „Availability” indicator values with the function of the trend in the study period

Source: own study

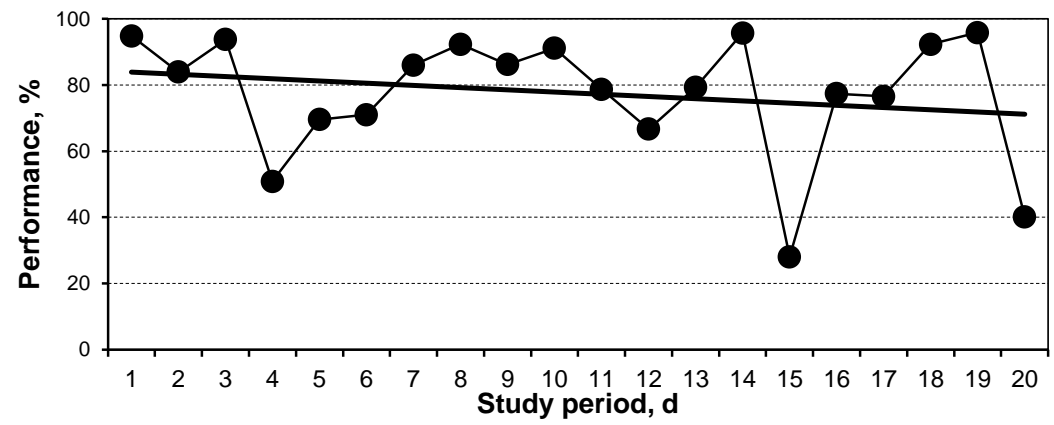

Fig.3. The distribution of „Performance” indicator values with the function of Source: own study the trend in the study period 


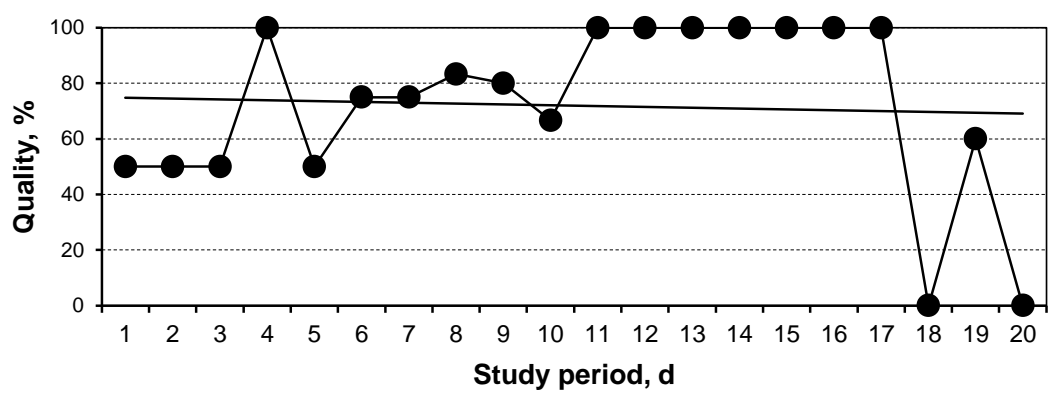

Fig.4. The distribution of „Quality” indicator values with the function of the trend in the study period

Source: own study

In Fig.6.5. the distribution of OEE indicator values with the function of the trend in the study period has been presented. As the graph shows about half the days of the period of time reported OEE value less than $50 \%$ percent, and average value of OEE indicator for 20-day study period for induction furnace was $44.6 \%$ (Fig.6), which is significantly lower value than implied by world standards. Such a large discrepancy in the values of indicators: availability, quality and performance, mainly due to the type of manufactured components.

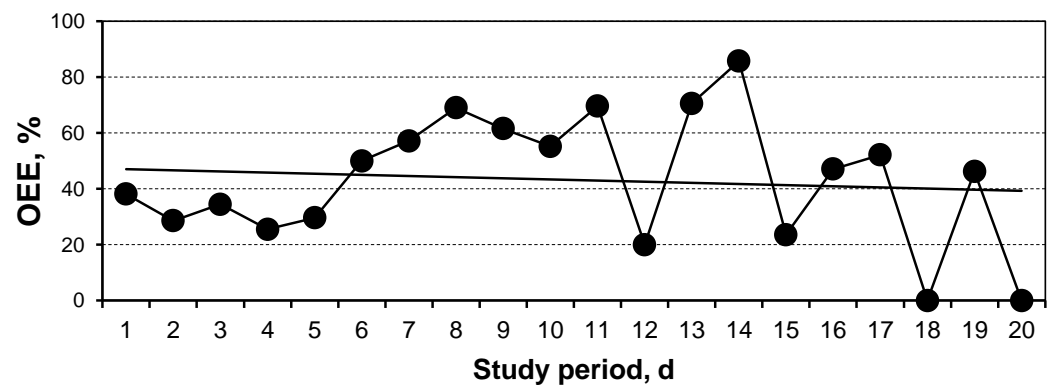

Fig.5. The distribution of $\mathrm{OEE}$ indicator values with the function of the trend Source: own study in the study period 


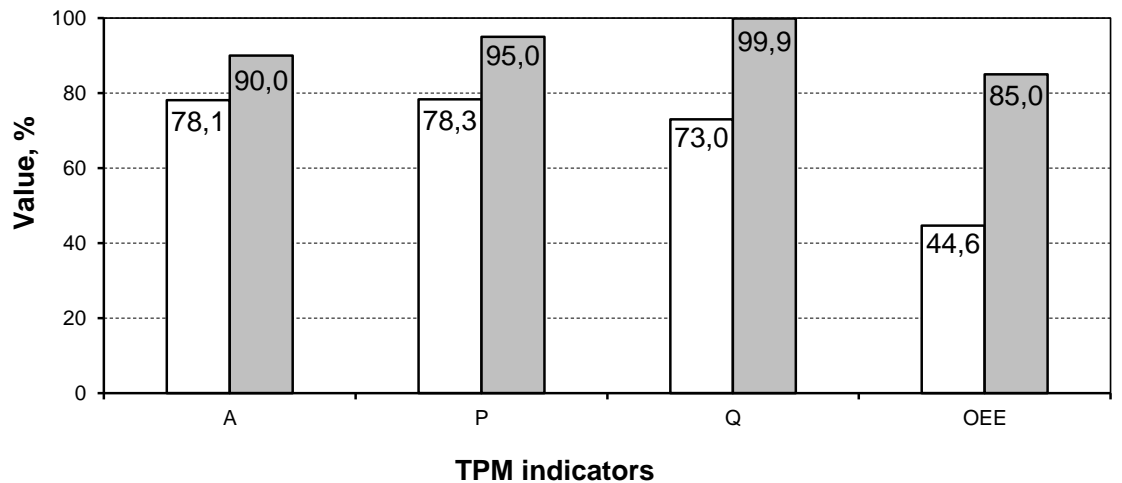

$\square$ Process $\square$ World Class

Fig.6. Comparison of TPM indicators values for the tested process according the world level (World Class OEE)

Source: own study

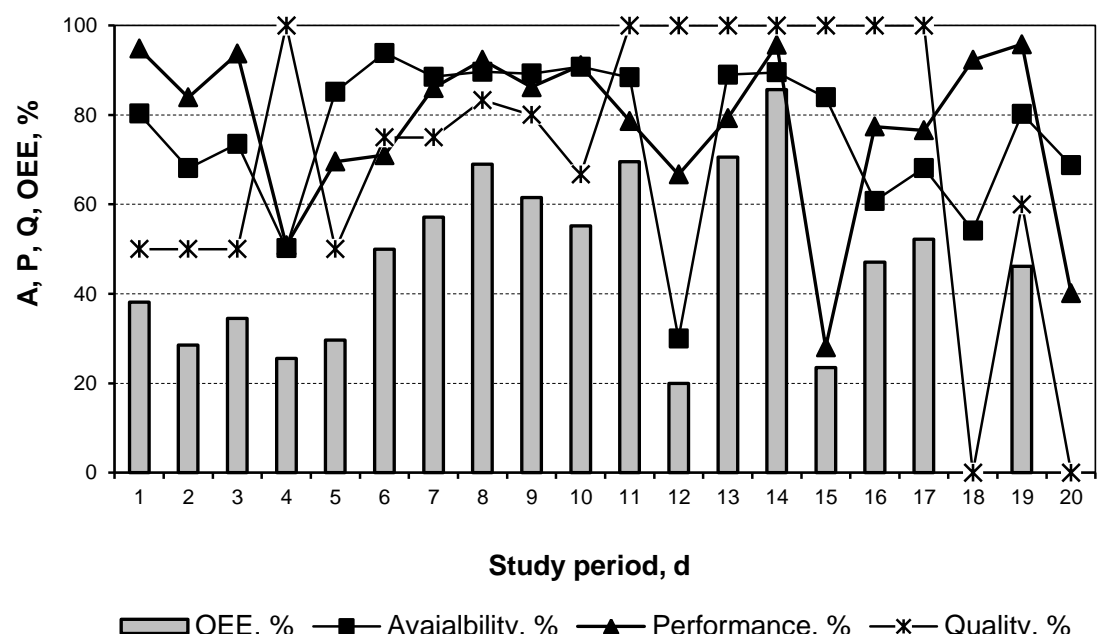

Fig 7. Distribution of TPM indicators values in the study period

Source: own study 


\subsection{Summary}

The distribution OEE indicator values shows that about the half days of the time period reported OEE value less than 50\% percent, and average value of OEE indicator for 20-day study period for induction furnace was $44.6 \%$. All indicators values are characterized with significantly lower value than implied by world standards. Such a large discrepancy in the values of indicators: availability, quality and performance, mainly due to the type of manufactured components. The production had never showed $100 \%$ performance of the established manufacturing plan, most often the value fluctuated around $90 \%$, but in a few days there is marked a large decrease in production efficiency (Fig.8). Such large variations on the plan may cause a reduction in productivity of finished products. Based on the measurements, it was found that the best way to improve the performance of the machine is to increase the skills of workers operating the furnace, and the implementation of SMED techniques in machine retooling.

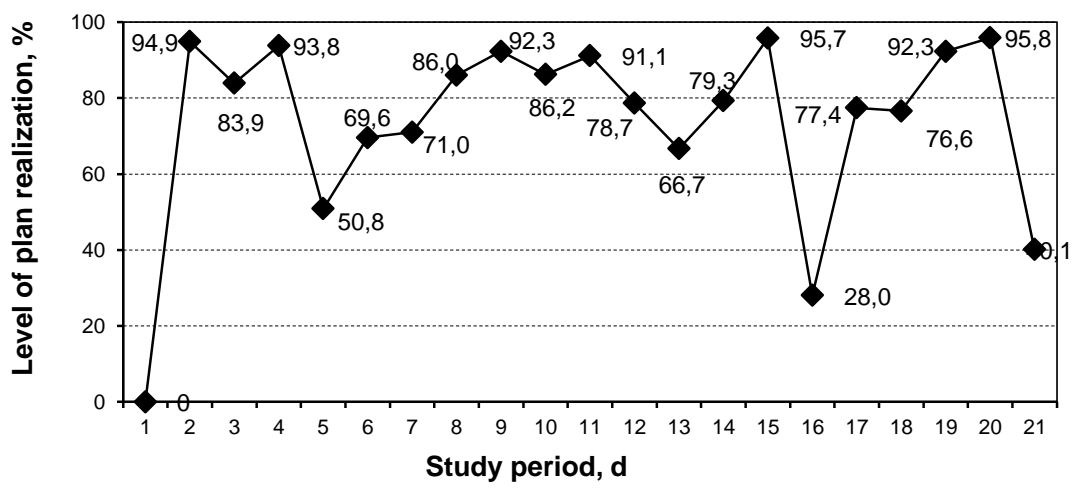

Fig. 8. The level of the production plan realization In the stuydy period

Source: own study 


\section{Bibligraphy}

1. DobrZAŃSKi L. A. 2009. Podstawy metodologii projektowania materiałowego. Wyd. Politechniki Śląskiej. Gliwice.

2. KORDASZ P., WOLANEK Z. 1983. Materiałoznawstwo protetycznostomatologiczne, PZWL,Warszawa.

3. MAJEWSKI ST. 2000. Podstawy protetyki w praktyce lekarskiej i technice dentystycznej. Wyd. SZS-W, Kraków.

4. ORLICKI R. , KŁAPTOCZ B. 2003. Inżynieria Stomatologiczna Biomateriały. Tom I nr 1, s. 3.

5. POLAK A. 2005. Teoretyczne podstawy i praktyczne wskazówki z zakresu odlewnictwa. Nowoczesny Technik Dentystyczny. Nr 2. s. 28-36.I

6. RAdOMSKa K., KlimeCKA-TATAR D. 2013. The Effect of Melting/Casting Method of Ni-Cr-Mo Dental Alloy on the Corrosion Resistance in Ringer Solution. Corrosion Protection R.56 nr 11. s. 527-530

7. ŚPIEWAK R., PIĘTOWSKA J. 2006. Nikiel - alergen wyjątkowy. Od struktury atomu do regulacji prawnych. Alergologia Immunologia 3 (3-4) s. 58-62 